\title{
Bridging the empathy gap: or not? Reactions to ingroup and outgroup facial expressions
}

\author{
Ursula Hess (D) Magdalena Rychlowska - Tobias Storz • Christophe Blaison • \\ Agneta Fischer • Eva G. Krumhuber
}

Received: 2 July 2021 / Revised: 15 February 2022 / Accepted: 16 February 2022 / Published online: 5 March 2022

(C) The Author(s) 2022

\begin{abstract}
Prior research suggests that group membership impacts behavioral and self-reported responses to others' facial expressions of emotion. In this paper, we examine how the mere labelling of a face as an ingroup or outgroup member affects facial mimicry (Study 1) and judgments of genuineness (Study 2). In addition, we test whether the effects of group membership on facial mimicry and perceived genuineness are moderated by the presence of tears (Study 1) and the motivation to cooperate (Study 2). Results from both studies revealed group-specific biases in facial mimicry and judgments of
\end{abstract}

U. Hess $(\bowtie)$

Department of Psychology, Humboldt University, Berlin, Germany

e-mail: Ursula.Hess@hu-berlin.de

M. Rychlowska

Queen's University Belfast, Belfast, UK

T. Storz · E. G. Krumhuber

University College London, London, UK

e-mail: tobias.storz@vivantes.de

Present Address:

T. Storz

Centre for Women's Mental Health, Vivantes Clinic

Spandau, Berlin, Germany

C. Blaison

University of Paris, Paris, France

A. Fischer

University of Amsterdam, Amsterdam, The Netherlands genuineness. However, introducing cooperative goals abolished differences in judgments of genuineness of facial expressions displayed by ingroup and outgroup members. Together, the findings provide insights into how intergroup biases in emotion perception operate and how they can be reduced by introducing cooperative goals.

Keywords Emotion - Facial expression - Outgroup · Tears $\cdot$ Cooperation

\section{Introduction}

Facial expressions are of paramount importance in the social world. We are moved and motivated by people's smiles, frowns and grimaces. They inform us about others' feelings and intentions, thereby influencing our own emotions and behaviors. Our daily interactions thus depend on the efficient perception and interpretation of emotion expressions (Niedenthal \& Brauer, 2012) as well as the adequate reaction to these expressions (Hess, 2021). Notably, the perception of others' expressions and our reactions are influenced by personal goals and motives, often defined by the social context (Hess \& Hareli, 2019) and in particular who our interaction partners are (Fischer et al., 2019; Hess \& Fischer, 2017). The present research examined how facial reactions to other people's emotion expressions and judgments of 
genuineness of these expressions are influenced by knowing that the expresser belongs to a different social group.

Group membership, in particular the distinction between ingroup and outgroup members, fundamentally shapes human interactions (Tajfel \& Turner, 1979) and influences emotion communication. Specifically, people tend to be more accurate when decoding emotional expressions of individuals belonging to their ingroup compared to expressions displayed by people from other backgrounds (Elfenbein \& Ambady, 2002; Elfenbein et al., 2007). This ingroup advantage can be partially explained by nonverbal dialects, i.e., subtle differences in the expressions displayed by members of different cultures (Elfenbein et al., 2007), as well as by cross-cultural variations in facial appearance (Beaupré \& Hess, 2005). However, as this effect persists when the expresser and the observer belong to the same ethnic and cultural group, and even in minimal group settings, where subjects are randomly assigned to meaningless groups. For example, Young and Hugenberg (2010) found participants to be judge the same facial expressions more accurately when those were ostensibly shown by ingroup rather than outgroup members. Thus, simply labelling faces made participants see them differently. Similarly, Thibault et al. (2006) found that basketball players were more accurate in decoding expressions of people claimed to be fellow basketball players rather than other students.

There are several explanations for the ingroup advantage in emotion communication. First, faces are embedded within a larger context that provides information about the expresser and the situation in which the emotion occurs. Thus, people have expectations about which emotions should be displayed by members of different groups (Kirouac \& Hess, 1999). Such conceptual knowledge of emotions has been shown to affect early stages of expression recognition (Bijlstra et al., 2014; Hugenberg \& Bodenhausen, 2003; Young \& Hugenberg, 2010). Second, people are more motivated to understand the emotions of their ingroup members (Thibault et al., 2006). Outgroup faces, compared to those of ingroup members, seem to cue cognitive disregard associated with less accurate face perception (Rodin, 1987). Moreover, increasing the motivation to decode expressions through monetary incentives was found to improve decoding accuracy and increase affiliative facial responses
(Hess et al., Hess, Blaison, et al., 2017). It is also possible that honest and highly salient emotion signals such as tears can increase the motivation to correctly decode outgroup faces. Such signals have been shown to boost empathy (Fischer \& Manstead, 2008; Hendriks et al., 2008).

In the present studies, we examine how facial mimicry of other people's expressions and judgments of genuineness of these expressions are influenced by group membership. These two facets were chosen due to their importance for empathic (i.e., warm and trustful) interactions. For such interactions to occur, people need to appropriately react to others' expressions and correctly interpret these displays. One common behavioral response to others' emotion expressions is emotional or facial mimicry, which represents the specific case of the imitation of facial expressions. The 'mimicry as social regulator model' (Fischer \& Hess, 2017; Hess \& Fischer, 2013, 2014) considers facial mimicry as a social act that is influenced by the context of the interaction and the social goals of the person who imitates. Importantly, mimicry of affiliative expressions improves the perceived interaction quality, whereas mimicry of antagonistic expressions reduce it (Mauersberger \& Hess, 2019). Moreover, whether a given expression is perceived as appropriate in a given context strongly moderates mimicry (Kastendieck et al., 2020).

There is evidence that people put greater trust in ingroup than outgroup members (Balliet et al., 2014). It is plausible that this tendency also extends to the perception of authenticity or genuineness of facial expressions which constitutes a basis for establishing interpersonal trust (Krumhuber et al., 2007). Both facial mimicry and perceived genuineness are highly relevant in intergroup contexts. If mimicry is absent or if the expression of an outgroup member is perceived as non-authentic (hence untrustworthy), a pernicious effect on interactions can be expected, potentially resulting in what we describe as empathy gap. We use this term to describe the notion that not only are outgroup facial expressions more likely to be decoded less accurately but also more likely to elicit less empathy as indexed by reduced mimicry of out-group expressions.

Beyond examining the potential intergroup empathy gap, the second aim of this research is to consider means of reducing it. It has been suggested that tears function to elicit empathy and support (Fischer \& 
Manstead, 2008; Hendriks et al., 2008), evoking positive reactions in others (Hendriks \& Vingerhoets, 2006). As such, tears may reduce the distance with which outgroup members are often viewed. Yet, at the same time, they may also appear inappropriate (Warner \& Shields, 2007), and therefore elicit less mimicry (Kastendieck et al., 2020) and widen the perceived distance between groups. To investigate the potentially positive role of tears in this context, we manipulated their presence in Study 1. In Study 2, we aimed to bridge the empathy gap using a cooperation task. Cooperation goals can alleviate intergroup bias (Allport, 1954) and potentially increase the motivation to correctly interpret the outgroup faces and their expressions. For example, in a study by Bettencourt et al. (1992), participants allocated more resources to outgroup members and described them as more friendly and competent when they had been instructed to cooperate, rather than compete, with the outgroup. Similarly, imagining a cooperative (vs. competitive) interaction with an outgroup member increased trust and empathy toward the outgroup (Kuchenbrandt et al., 2013). As such, inducing cooperative goals can be a means to bridge the empathy gap.

The present research

We examined how group membership affected two predictors of trusting interactions: facial mimicry and perceived genuineness of facial expressions. We also assessed whether tears (Study 1) or the motivation to cooperate (Study 2) would alleviate such effects. For this purpose, we labeled expressions displayed by same-race individuals as produced by ingroup versus outgroup members. Specifically, we recruited individuals who considered themselves football (soccer) fans and who identified with the German national team (Study 1) or the Arsenal Football Club (Study 2). We then presented the stimulus faces labeled as fans of the same versus a competing football team who react to the performance of their club. We thus introduced real-life groups that were highly relevant to participants. In Study 1, German football supporters saw individuals presented as fans of the Dutch or German national teams reacting to a loss or win of their team. Participants judged the emotion expressions of the "fans" and facial mimicry was recorded. In Study 2, supporters of the Arsenal Football Club saw faces of individuals presented as fellow Arsenal fans or fans of a competing team (Tottenham Hotspur). The task was couched in terms of cooperation goals for half the group. Here, we focused on the perceived authenticity of emotion expressions as a function of group membership. Study 1 compared participants' reactions to high-intensity and low-intensity expressions, and Study 2 focused on low-intensity expressions only. Low intensity expressions were used as they are more ambiguous and therefore more difficult to decode and potentially more likely to tap motivated processing.

\section{Study 1}

Method

\section{Participants}

A total of 91 German men were recruited from the participant pool at Humboldt-University of Berlin and participated individually. We specifically recruited participants who were interested in German football. Data from one participant was lost due to technical problems, resulting in a final sample of 90 participants $\left(M_{\text {age }}=27.7\right.$ years, $\left.S D 7.4\right)$. With this sample size, the study had $90 \%$ power to detect an effect of $\eta_{p}^{2}=0.10$ for the mimicry analysis. ${ }^{1}$ Data from our laboratory show that mimicry effects tend to range from $\eta_{\mathrm{p}}^{2}=0.15$ to $\eta_{\mathrm{p}}^{2}=0.30$. Hence, the study should have adequate power to detect mimicry effects.

\section{Design}

The experiment used a mixed design with emotion expression (sad, $n=45$, happy, $n=45$ ) and group membership (ingroup: supporters of German national team, outgroup: supporters of Dutch national team) as between-subjects factors and presence of tears (present, absent) as well as expression intensity (low vs. high) as within-subjects factors.

\footnotetext{
${ }^{1}$ The focal analysis for the mimicry effect is the contrast combining the three muscles in the group membership in one of the expression intensity conditions at one time-point. This resolves to 4 measurement groups with two measurements by group. This yields an $\mathrm{f}$ of .30 which in turn corresponds to an $\eta_{\mathrm{p}}{ }^{2}=.10($ and a $d=.66)$.
} 


\section{Facial Stimuli}

Participants saw happy or sad expressions shown by ingroup or outgroup members, with the explanation that these individuals' favorite football team had either won (happy expression condition) or lost (sad expression condition). The cover story matched the expression such that in the happy ingroup condition participants learned that the German national team has won the match and saw smiling supporters of the German team. Conversely, in the sad ingroup condition, participants learned that the German team lost the match and saw sad supporters of this team. Participants in the outgroup condition saw supporters of the Dutch national team reacting to the win or loss of their team. Photographs of facial expressions of happiness and sadness shown by 8 men were taken from the Karolinska Directed Emotional Faces set (KDEF; Lundqvist et al., 1998). In addition to happiness and sadness, we used plausible filler items as it may be curious to only see one emotional reaction shown by everyone. For the happy expression condition, surprise was used as a filler and for the sad expression condition, anger; neutral expressions were used in both conditions. Tears were added with Photoshop to produce a version with and without tears for all sad and happy expressions. All expressions were presented either at $100 \%$ intensity (high intensity condition) or morphed with neutral expressions to $60 \%$ intensity (low intensity condition). In each condition, subjects saw 16 photographs. In the sad condition, participants saw 8 sad expressions by 8 different actors as well as four angry and four neutral expressions by the same 8 actors. Participants never saw the same person with and without tears. In the happy condition, participants saw eight happy expressions as well as four surprised and four neutral expressions. Actors were counterbalanced across participants.

\section{Procedure}

Upon arrival at the laboratory, the participants were informed about the procedure and signed a consent form. They were then seated in a comfortable chair and EMG electrodes were attached on the left side of their face. We recorded facial EMG at the Corrugator supercilii (frown), Orbicularis oculi (wrinkles around the eyes), Levator Labii (lifting the upper lip in disgust), and the Zygomaticus major (lifting the corners of the mouth in a smile) muscle sites using bipolar placements of Easycap $\mathrm{GmbH} \mathrm{Ag} / \mathrm{AgCl}$ miniature surface electrodes filled with Signa Gel by Parker Laboratories Inc. The skin was cleansed with Lemon Prep peeling paste and 70\% alcohol. Impedances were kept below $30 \mathrm{k} \Omega$.

Participants were then told that their task was to assess the emotions of football fans reacting to the results of a football game. They were then provided with the cover story, which mentioned the teams (Dutch national team and German national team) as well as the adversary in the game and who won the match. Correspondingly participants saw either ingroup (German) or outgroup (Dutch) "fans" who showed either happy (if the team won) or sad (if it lost) expressions.

Participants first saw a relaxing 3.5 min video, while a baseline period for EMG measures was recorded. They then saw the 16 photos presented in random order. Each image was presented for $5 \mathrm{~s}$ and followed by the rating scales. Specifically, participants rated the perceived intensity of the expressions on each of the following 7-point scales anchored with 1not at all and 7-very much: happiness, anger, sadness, fear, disgust, and surprise. Prior to debriefing they rated the extent to which they considered themselves football fans (1-not at all to 5-very much) and provided sociodemographic information.

\section{Data preprocessing and artifact control}

Raw EMG data were sampled using a Mind Ware bioamplifier with a $50 \mathrm{~Hz}$ notch filter at $1000 \mathrm{~Hz}$. The signals were band pass filtered between 30 and $300 \mathrm{~Hz}$, offline rectified and smoothed. The video records for all participants were inspected for movements such as yawning, coughing or sneezing that could disrupt the EMG measures. Periods corresponding to such movements were set missing and excluded from further analyses. Within-subject z-transformed difference scores (trial-baseline) were calculated, to control for the individuals' general expressiveness (their general level of facial activity). Data were averaged across $1 \mathrm{~s}$ bins for each trial because previous research has shown that mimicry follows a time course (e.g., Dimberg et al., 2002).

We then used these scores to examine participants' facial mimicry in reaction to emotions displayed by ingroup and outgroup members. Sadness mimicry was 
indexed by increased activity of the Corrugator S. muscle combined with decreased activity of the muscles O. Oculi and Zygomaticus M. The reverse pattern indicated smiling. Increased activity of Corrugator $\mathrm{S}$. in combination with increased $\mathrm{O}$. Oculi and decreased Zygomaticus M. was indicative of mirroring a cry face with squinting eyes. The activity of Levator L. is outside the focus of the present article and will be excluded from the analyses.

\section{Results and discussion}

\section{Interest in German Football}

In reaction to the question assessing self-reported interest in German football, participants identified as football fans with a mean of 4.08 (SD 0.92), with $40 \%$ indicating a score of 5 .

\section{Perceived intensity of emotion expressions}

We first assessed whether group membership and the presence of tears had an influence on the perception of facial expressions. As we were not interested in the theoretically trivial differences between ratings of happy and sad expressions, we examined these conditions separately. For each expression, we conducted two analyses of variance examining ratings of happiness and sadness as a function of group membership (manipulated between subjects), presence of tears, and expression intensity (both manipulated within subjects).

Sadness ratings For sad expressions, significant main effects of tears, $F(1,44)=74.53, p<0.001$, $\eta_{\mathrm{p}}^{2}=0.63$ and intensity, $F(1,44)=19.41, p<0.001$, $\eta_{\mathrm{p}}^{2}=0.31$, emerged. High-intensity sad expressions with tears were rated as sadder (see Table 1 for descriptive statistics). However, a significant tears by intensity interaction, $F(1,44)=4.15, \quad p=0.048$, $\eta_{\mathrm{p}}^{2}=0.09$, suggests that the effect of tears was stronger for low-intensity expressions. Neither the main effect of the group membership nor interactions involving this variable were significant.

For happy expressions, we observed significant main effects of tears, $F(1,43)=27.44, p<0.001$, $\eta_{\mathrm{p}}^{2}=0.39$, and intensity, $F(1,43)=23.27, p<0.001$, $\eta_{\mathrm{p}}^{2}=0.35$. Specifically, happy expressions with tears were rated as sadder than those without tears, and lowintensity expressions were rated as sadder than highintensity expressions. No other main effects of interactions emerged significantly.

Happiness ratings For happy expressions, a main effect of intensity, $F(1,43)=106.20, p<0.001$, $\eta_{\mathrm{p}}^{2}=0.71$, emerged, such that more intense expressions were perceived as happier. This was qualified by an intensity $\times$ group interaction, $F(1,43)=10.63, p=0.002, \eta_{\mathrm{p}}^{2}=0.20$, such that the effect of intensity was larger for ingroup members than for outgroup members. No further main effects or interactions emerged for happy expressions. For sad expressions, no significant main effects or interactions emerged.

In sum, group membership had almost no effect on emotion expressions ratings. However, it should be noted that participants were told that the fans presented in the stimuli reacted to a win or a loss of their team. Since a win by a favored team generally leads to happiness and a loss of such team is more likely to entrain sadness, it is plausible that participants used this rule to assess the fans' likely emotion and were less influenced by other factors, such as who the fans supported, the presence of tears, or the intensity of facial expressions displayed.

Consistent with this interpretation, group membership moderated the effects of intensity for happiness ratings of happy expressions. Specifically, the difference between high- and low-intensity displays was less marked for outgroup compared to ingroup members. This interaction suggests that participants disregarded the facial expression information of outgroup members in favor of the situational information provided. Tears intensified sadness for sad expressions in response to the loss of the favorite football team for both ingroup and outgroup members. Interestingly, however, happy expressions combined with tears were also rated as sadder than happy expressions without tears. That is, not only did "happy tears" not increase happiness about the purported win of the own team, but they rather increased sadness, resulting in a mixed emotion expression. 
Table 1 Emotion ratings for ingroup and outgroup expressions of happiness and sadness

\begin{tabular}{|c|c|c|c|c|}
\hline & \multicolumn{2}{|l|}{ Tears } & \multicolumn{2}{|l|}{ No tears } \\
\hline & High intensity & Low intensity & High intensity & Low intensity \\
\hline \multicolumn{5}{|c|}{ Sad expressions, ratings of sadness } \\
\hline Ingroup & $5.54(1.13)$ & $4.30(1.56)$ & $6.07(1.06)$ & $4.02(1.25)$ \\
\hline Outgroup & $5.59(1.12)$ & $4.86(1.54)$ & $5.77(0.69)$ & $4.80(1.23)$ \\
\hline \multicolumn{5}{|c|}{ Happy expressions, ratings of happiness } \\
\hline Ingroup & $6.33(0.75)$ & $6.09(0.72)$ & $5.48(0.99)$ & $4.96(1.44)$ \\
\hline Outgroup & $6.59(0.49)$ & $6.48(0.55)$ & $5.57(1.11)$ & $4.98(1.06)$ \\
\hline
\end{tabular}

\section{Facial EMG}

Preliminary analysis We first conducted a preliminary 3 (muscle site) $\times 4$ (time in seconds $) \times 2$ (emotion expression $) \times 2$ (group) $\times 2$ (intensity) $\times 2$ (presence of tears) mixed analysis of variance on the $\mathrm{z}$-transformed difference scores (trial-baseline). Consistent with the time course of the mimicry reaction observed in previous research (e.g., Dimberg et al., 2002), a significant main effect of time emerged, $F(3,80)=6.65, p<0.001, \eta_{\mathrm{p}}^{2}=0.20$. In addition, we observed significant interactions between muscle site and time, $F(6,77)=10.13$, $p<0.001, \eta_{\mathrm{p}}^{2}=0.44$, tears and emotion expression, $F(3,80)=4.78, \quad p=0.011, \quad \eta_{\mathrm{p}}^{2}=0.11, \quad$ intensity, emotion expression, and group, $F(1,82)=4.59$, $p=0.035, \eta_{\mathrm{p}}^{2}=0.05$, tears, muscle site, and group, $F(1,81)=4.24, p=0.018, \eta_{\mathrm{p}}^{2}=0.10$, muscle site, time, and group, $F(1,81)=2.67, \quad p=0.021$, $\eta_{\mathrm{p}}^{2}=0.17$, muscle site, time, group, and emotion, $F(6,77)=2.62, p=0.023, \eta_{\mathrm{p}}^{2}=0.17$. All of these were qualified by a significant six-way interaction between muscle site, time, emotion expression, group, intensity, and tears, $F(6,77)=4.24, p=0.023$, $\eta_{\mathrm{p}}^{2}=0.17$.

Simple effects analyses were conducted to follow up on this interaction. Specifically, we conducted a muscle site by time analysis of variance separately for each expression, group membership, intensity, and tears condition. Figure 1 shows means and standard errors of standardized EMG activity across the 16 experimental conditions. As mentioned earlier, participants' facial mimicry was assessed based on the activity of Corrugator S., O. Oculi, and Zygomaticus M. muscles. Mimicry of happiness is evidenced by increased O. Oculi and Zygomaticus M. and decreased
Corrugator S. activity, mimicry of sadness-by the converse pattern. One way to capture these predicted patterns of expression in a single metric is to calculate a contrast score in which Corrugator $\mathrm{S}$. is subtracted from the mean of O. Oculi and Zygomaticus M. (Hess et al., Hess, Arslan, et al., 2017). A negative score indexes a sad expression, whereas a positive score indexes a happy expression. To assess mimicry, we used the corresponding Helmert contrast for the muscle site factor.

Facial reactions to happy expressions For lowintensity happy expressions without tears (Fig. 1a, upper sections), a contrast indicating smile mimicry (decreased Corrugator S. combined with increased O. Oculi and Zygomaticus M.) was significant for time 4 $(t=1.97, p=0.05)$ only for ingroup expressions. Conversely, for outgroup expressions, a contrast indicating a negative emotion expression (i.e., increased Corrugator S. combined with decreased $\mathrm{O}$. Oculi and Zygomaticus M.) emerged significantly for time $1 \quad(t=3.14, p=0.002)$ and $2(t=2.33$, $p=0.020)$.

For low-intensity happy expressions with tears (Fig. 1c, upper sections), a contrast indicating a negative emotion expression emerged significantly for time $1 \quad(t=2.90, \quad p=0.004), 2 \quad(t=2.07$, $p=0.039)$, and $3(t=2.65, p=0.008)$ for ingroup expressions, and for time $1(t=3.57, p<0.001), 2$ $(t=2.13, p=0.034), 3(t=2.10, p=0.036)$, and 4 $(t=2.20, p=0.029)$ for outgroup expressions.

For high-intensity happy expressions without tears (Fig. 1b, upper sections), a contrast indicating smile mimicry emerged significantly at time $3(t=2.46$, $p=0.014)$ and $4(t=4.54, p<0.001)$ for ingroup expressions; the converse contrast emerged at time 1 $(t=1.99, p=0.047)$. For outgroup expressions a 
(a)

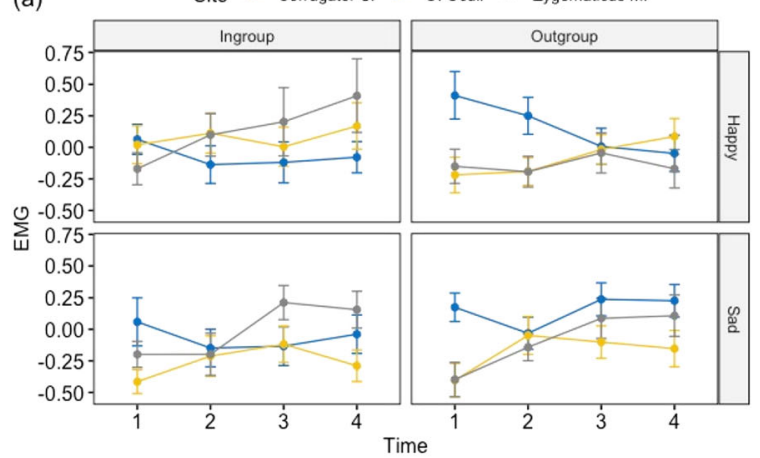

(b)

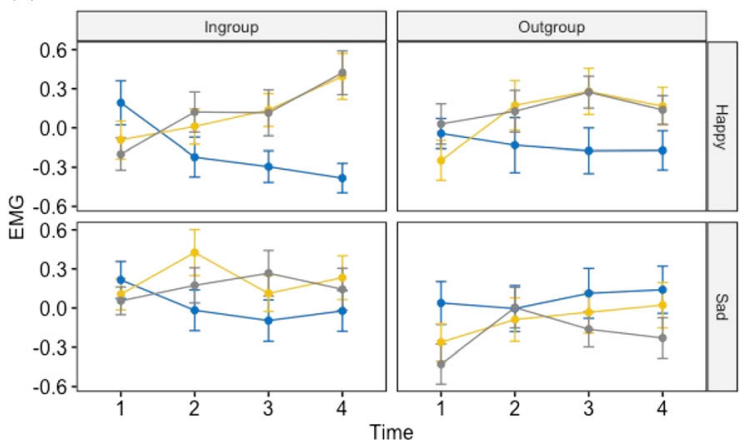

Fig. 1 Study 1: Standardized EMG scores as a function of muscle site, time, group membership, and emotion expression. A, b present reactions to expressions without tears with low-

contrast indicating smile mimicry emerged for time 3 $(t=2.57, p=0.010)$ only.

For high-intensity happy expressions with tears (Fig. 1d, upper sections), no significant contrast emerged for ingroups. For outgroup expressions, a contrast indicating smile mimicry emerged significantly for time $2(t=3.21, p=0.001), 3(t=4.09$, $p<0.001)$ and $4(t=3.04, p=0.003)$.

In sum, smiles displayed by ingroup members and not accompanied by tears were mimicked to some extent. When tears were present, smiles elicited either a negative mimicry reaction or no reaction. This might suggest that participants found tears in combination with happy expressions not appropriate. It should be noted that smiles accompanied by tears were also rated as somewhat sadder. It is plausible that such expressions were perceived as expressing mixed emotions in a situation that demands happiness, i.e. the winning of the own team. As such, these expressions would have been considered inappropriate to the situation. Similarly, the weak mimicry of low-intensity smiles

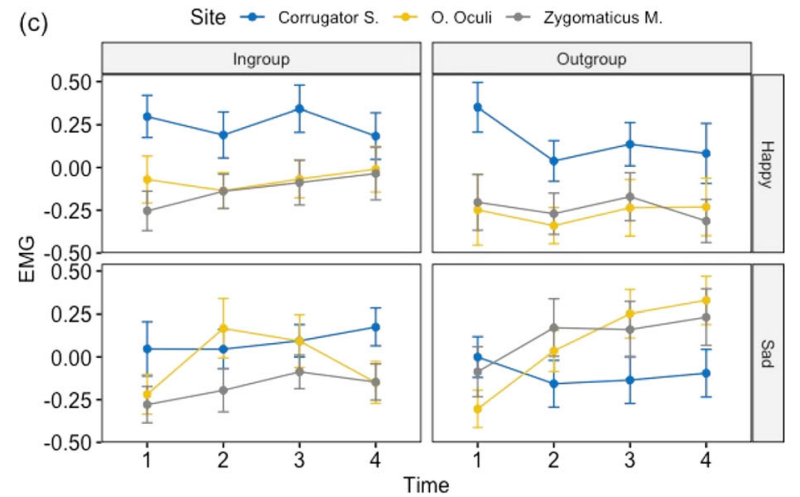

(d)

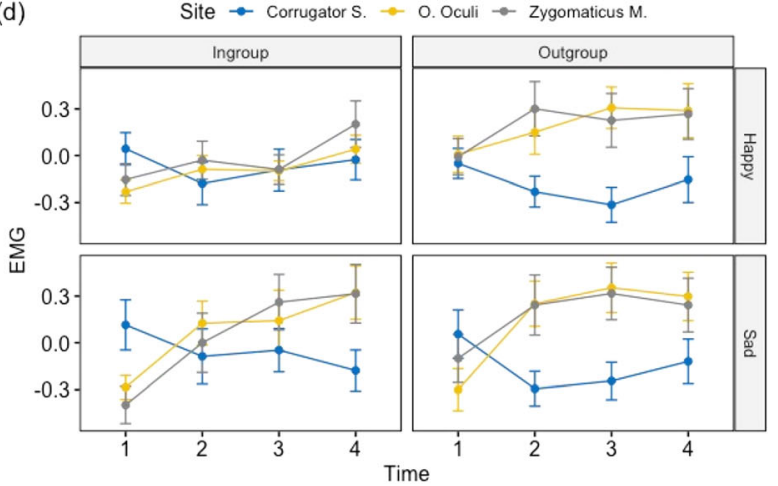

intensity expressions in a and high-intensity expressions in b. c, d present reactions to expressions with tears, low-intensity in c and high-intensity in $\mathbf{d}$

without tears might be because a slight smile is also not perceived as an appropriate reaction to the winning of one's own team. As noted above, inappropriate emotion displays tend to be mimicked less or not at all and might even elicit negative emotional reactions (Kastendieck et al., 2020).

For outgroup expressions, an interesting pattern emerged. Seeing low-intensity happy expressions, with and without tears, elicited negative facial expressions in participants. This is not surprising given that in the happy outgroup conditions the cover story indicated that the outgroup team had won, i.e., participants' own team lost. Such counter-mimicry has been observed in other studies in which competition was salient (Lanzetta \& Englis, 1989; Weyers et al., 2009). Yet, for high-intensity happy expressions, both with and without tears, an unexpected smiling expression was observed.

Facial reactions to sad expressions For lowintensity sadness expressions without tears (Fig. 1a, 
lower sections), a contrast indicating mimicry of sadness emerged for both ingroup $(t=2.31$, $p=0.021)$ and outgroup $(t=3.63, \quad p<0.001)$ expressions only at time 1 .

For low-intensity sadness expressions with tears (Fig. 1c, lower sections), the contrast indexing expressions of sadness only emerged significantly at time 4 $(t=2.05, p=0.041)$. However, the increase in $\mathrm{O}$. Oculi at time 2 and 3 , which was significantly higher than Zygomaticus M. at time $2(t=1.99, p=0.047)$, could suggest mimicry of crying. Importantly, for expressions displayed by outgroup faces, a contrast reflecting smiles was significant for time $3(t=2.17$, $p=0.030)$ and $4(t=2.39, p=0.017)$.

For high-intensity sad expressions without tears (Fig. 1b, lower sections), no significant contrasts emerged for ingroup expressions. For outgroup expressions, a contrast indicative of sadness emerged for time $1(t=2.27, p=0.024)$ only.

For high-intensity sadness expressions with tears (Fig. 1d, lower sections), a contrast indexing mimicry of sadness emerged significantly for ingroup expressions for time $1(t=2.48, p=0.014)$. However, at time $4(t=2.70, p=0.007)$ a smile expression was indexed significantly. For outgroup expressions, the smile contrast was significant for $2(t=2.94$, $p=0.003), 3(t=3.15, p=0.002)$, and $4(t=2.11$, $p=0.035$ ).

The analysis of facial reactions to expressions of sadness indicates that participants tended to mimic low-intensity ingroup expressions, especially those with tears. Yet, for high-intensity sad expressions with tears, we observed a smiling reaction. Moreover, sad and teary expressions displayed by outgroup members elicited reactions of smiling, independently of their intensity. This pattern suggests that participants found high-intensity sadness expressions, especially those accompanied by tears, amusing rather than empathyinducing. This was the case even for ingroup members. Sad expressions are signs of weakness as they imply an appeal for help (Scarantino, 2019). Strong sadness may thus have been perceived as inappropriate for fellow football fans. As such, smiling in reaction to inappropriate displays of sadness is congruent with the notion that socially unacceptable expressions are not mimicked and might even elicit contrasting reactions (Kastendieck et al., 2020).

It is notable that low intensity-expressions with tears seemed to elicit some mimicry when shown by ingroup members. However, Warner and Shields (2007) note that restrained and controlled expressions of sadness in men are perceived relatively positively. In fact, signs of restraint might even be considered indicative of emotional intelligence in men (Hess et al., 2016). As such, low-intensity sadness expressions might have been deemed appropriate, especially in a sports context, where tears are more acceptable overall (MacArthur \& Shields, 2015).

Summarizing the EMG findings, participants did not consistently mimic expressions by either the ingroup or the outgroup members. In fact, our findings highlight top-down effects of situational context on emotional mimicry. Given the social context information about the event that supposedly elicited the expressions, both the intensity of the expression and the presence of tears were relevant moderators of mimicry. In particular, mimicry of low-intensity expressions of happiness and high-intensity expressions of sadness displayed by ingroup members was reduced, potentially because such expressions could be considered less appropriate for the ingroup. Notably, tears in conjunction with happy expressions did not increase mimicry. As tearful smiles were also rated as expressing some sadness, they may have been interpreted as a mixed emotional reaction, which could be considered inappropriate for a clearly positive event.

For the outgroup, clear indications of mimicry were limited to high-intensity happy expressions. Happy expressions are mimicked quite often, even when shown by outgroup members (Bourgeois \& Hess, 2008). Notably, contrary to the notion that tears can bridge the empathy gap for outgroup members, teary outgroup expressions seemed to, if anything, elicit amusement. In fact, it remains possible that the "mimicry" of teary high intensity happy expressions also reflects amusement rather than true mimicry.

\section{Study 2}

Study 1 suggests that ingroup expressions are mimicked to a larger extent than outgroup expressions. However, both ingroup and outgroup mimicry were also impacted by the social context of the situation, with expressions potentially perceived as inappropriate being mimicked to a lesser degree. Overall, tears 
did not seem to have a bridging effect on intergroup communication.

Study 2 adopted a different paradigm, focusing on self-reported perceptions of ingroup and outgroup facial expressions. Specifically, we assessed whether expressions shown by outgroup members are perceived as less genuine and whether introducing a shared cooperation goal would affect this judgment. For this purpose, participants were primed either with cooperation goals or did a neutral prime task. We also extended the range of emotions considered. Given that the first study implied that high-intensity expressions of sadness were potentially too extreme, Study 2 included only lower intensity expressions.

\section{Method}

\section{Participants}

Male White supporters (18-41 years) of the Arsenal Football Club (AFC) in the United Kingdom were recruited through opportunity sampling in front of the Emirates stadium in Northern London and provided their email address for participation in an online study. In addition, we advertised the study online by inviting the chairmen of several Arsenal supporter clubs in the UK, Ireland, and the USA to distribute the survey link among their members. We only considered data from participants who showed moderate to high identification levels with AFC (scores 4-7 on a 7-point scale) and low identification (scores 1-3 on 7-point scale) with other UK clubs (i.e., Liverpool FC, Manchester United, Tottenham Hotspur). Two participants who indicated suspicion about the study hypothesis were excluded from data analysis. This left a final sample of 84 participants with a mean age of 28.78 years $(S D$ 5.89). A priori power analysis using $\mathrm{G}^{*}$ Power (version 3.1.9; Faul et al., 2009) indicated that 84 participants would be sufficient to detect a medium-sized interaction effect (Cohen's $f=0.25$ ) with $99 \%$ power $(\alpha=0.05)$ in a mixed ANOVA (Football team: Arsenal vs. Tottenham as within-subject factor and Condition: control vs. cooperation goal as betweensubject factor). The outgroup team (Tottenham) was chosen because of the rivalry between the two North London based teams, often described as one of the fiercest in English football.

\section{Materials}

Facial stimuli Twenty-seven White male faces with a neutral expression were taken from the Amsterdam Dynamic Facial Expression Set (ADFES; van der Schalk et al., 2011a) and the Radboud Faces Database (RaFD; Langner et al., 2010). The 27 neutral faces were pre-tested by a separate group of participants $(N=17)$ who rated the trustworthiness, likeability, attractiveness and sociability of each face on a scale ranging from 1 (very untrustworthy) to 7 (very trustworthy). Eight facial targets which were matched on the four traits (trustworthiness, $M=3.96$; likeability, $\quad M=4.01$; attractiveness, $M=3.25$; sociability, $M=4.04$ ) were selected for the main study, with each of them showing four different expressions: happiness, anger, sadness, and fear. To make the expressions more subtle in appearance, facial stimuli of $40 \%$ emotional intensity were created by morphing between the neutral and the peak emotional display using Abrosoft FantaMorph software.

Group identification The Overlap of Self, Ingroup, and Outgroup (OSIO) questionnaire (Schubert \& Otten, 2002), a modified version of the Inclusion of Other in Self (IOS) scale (Aron et al., 1992), was used to assess identification with the ingroup (Arsenal FC) and the outgroup (Liverpool FC, Manchester United, Tottenham Hotspur). For this, participants indicated on a 7-point visual analogue scale (1-no overlap, 7complete overlap) the overlap between two circles, one representing the self and one representing the football club. A greater degree of overlap on this scale is associated with increased group identification.

Cooperation goal task Cooperative motives were activated by means of a Scrambled Sentence Test (Costin, 1969; Watson et al., 1955). For this, each participant was given 15 scrambled sentences. Each scrambled sentence consisted of 5 words that were presented in a mixed order; for every five-word list one word was a distractor. Participants' task was to find the distractor word and to re-order the remaining four words such that they formed a grammatically correct English sentence. Participants in the control condition were presented with 15 sentences of neutral words unrelated to cooperation. For participants in the cooperation goal condition, 11 out of the 15 
sentences contained words related to cooperation (i.e., coalition, collaborate, support), with the remaining four sentences being neutral. Similar versions of the Scrambled Sentence Test have been successfully used in previous studies to activate cooperative motives and goals (Fitzsimons \& Shah, 2008; Sacco \& Hugenberg, 2012). In addition, participants in the cooperation goal condition were told that they would need to work together with a member of the outgroup for a subsequent task. It was made clear that this task requires mutual cooperation.

\section{Procedure and design}

After providing informed consent, participants were asked to select their favored Premier League club and to indicate their identification with the following clubs using a visual analogue scale: Arsenal FC, Liverpool FC, Manchester United and Tottenham Hotspur FC. Participants were then randomly assigned to the control condition $(N=40)$ or the cooperative goal condition $(N=44)$ by completing the respective versions of the Scrambled Sentence Test.

Next, they performed the genuineness rating task. For this, the total set of 32 images (4 emotions $\times 8$ targets) was subdivided into two blocks of 16 images each. Every block consisted of four targets, each expressing four emotions: happiness, anger, sadness and fear. We manipulated group membership by creating two different versions of each block: in one version the images bore the label 'Arsenal London FC' (ingroup), in the other version the images bore the label 'Tottenham Hotspur' (outgroup). That is, for each picture an ingroup and an outgroup version was produced. The different versions of the blocks were counterbalanced and presented in random order such that each participant saw 4 targets of the ingroup and 4 targets of the outgroup, each displaying four different expressions (happiness, anger, sadness, fear). Each facial image (display resolution: ADFES: $720 \times 576$ pixels, Radboud: $511 \times 768$ pixels) was shown for five seconds and immediately replaced by a judgement scale. For each image, participants were instructed to how genuine the expression appeared to be (7-point Likert scale with response options ranging from $1-$ very fake to 7-very genuine).
Results and discussion

A 2 (cooperation goal: control, cooperation) $\times 2$ (group membership: ingroup, outgroup) $\times 4$ (emotion expression: happiness, anger, sadness, fear) analysis of variance was conducted on the genuineness ratings. Figure 2 shows means and standard errors. A significant main effect of emotion, $F(3,80)=7.55$, $p<0.001, \eta_{\mathrm{p}}^{2}=0.22$, was qualified by interactions between emotion expression and goal condition, $F(3,80)=3.16, p=0.029, \eta_{p}^{2}=0.11$, and between emotion expression and group membership, $F(3,80)=4.94, p=0.003, \eta_{\mathrm{p}}^{2}=0.16$. These in turn were qualified by a three-way interaction between emotion expression, group membership, and goal condition, $F(3,80)=3.77, p=0.014, \eta_{p}^{2}=0.12$. Simple effects analyses revealed that in the control goal condition, happy $(t=2.80, p=008)$ and fear expressions $(t=2.32, p=0.025)$ were perceived as more genuine, whereas sad expressions $(t=2.06$, $p=0.046$ ) were perceived as less genuine when shown by the ingroup. No differences emerged for anger expressions. $(t=0.32, p=0.748)$. By contrast, when cooperation had been primed, no differences emerged (all $t$ 's $<1.00$, all $p$ 's $>0.500$ ).

Consistent with findings documenting increased trust for the ingroup (e.g., Brewer, 1999), participants evaluated ingroup expressions of happiness and fear as more genuine. Whereas ingroup smiles may reflect increased willingness to cooperate and share resources with one's group (Krumhuber et al., 2007), higher trust in fear expressions of the ingroup could be related to their importance as threat signals and displays that facilitate observational learning (Keltner \& Kring, 1998; Klinnert et al., 1983). No significant difference was observed for anger expressions. Interestingly, sadness was perceived as more genuine in outgroup faces. However, this may be due to a similar effect as observed in Study 1. As noted above, sadness signals weakness and participants may more readily accept signs of weakness from the outgroup of Tottenham supporters whereas similar manifestations of weakness were to some degree "rejected" when displayed by fellow Arsenal supporters.

Importantly, even though differences in perceived genuineness emerged for the neutral priming condition, these group differences entirely disappeared when a cooperation goal was primed. Specifically, as 
Fig. 2 Study 2: Mean genuineness ratings of the facial displays as a function of emotion expression, group membership, and cooperation goal (Study 2)

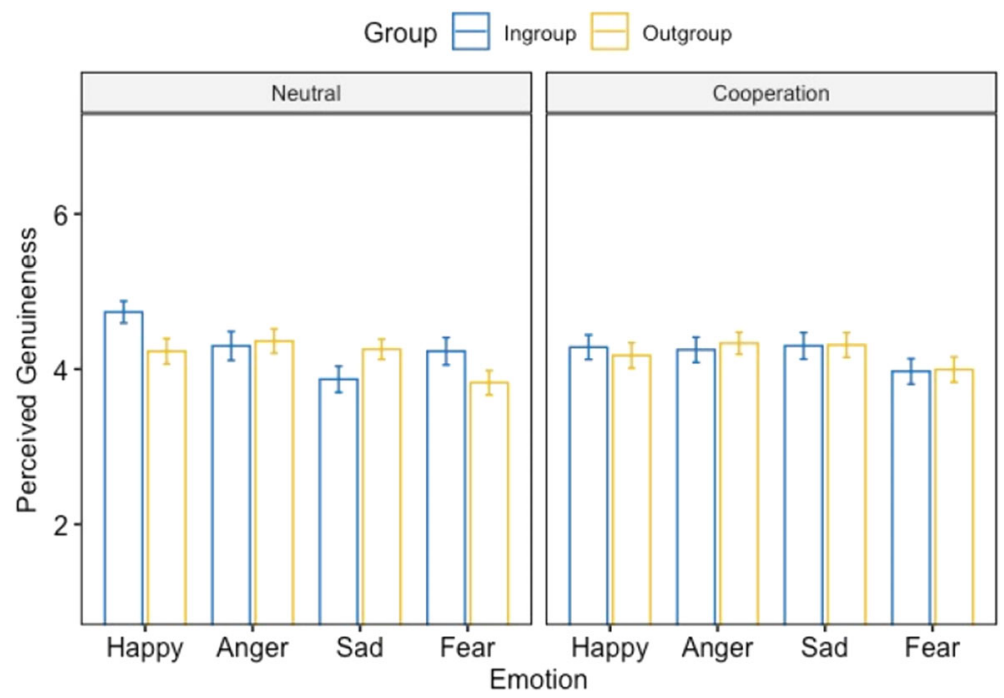

shown in Fig. 2, participants in the cooperative condition tended to judge ingroup smiles and fearful expressions as less genuine, and ingroup sadness as more genuine. Thus, priming participants with words related to cooperation and informing them that they were about to work together with an outgroup member was sufficient to eliminate group biases in emotion judgments. The finding is line with other research showing that motivational factors impact emotion decoding accuracy (Thibault et al., 2006) as well as empathic reactions in the form of facial mimicry (Hess et al., 2016). Here, changing participants' mindset by activating cooperation goals was sufficient to erase intergroup biases in ratings of expression genuineness. This was mainly due to a reduction in ingroup favoritism rather than a drop of outgroup derogation (Brewer, 1999).

\section{General discussion}

How does belonging to a group influence emotion communication? And can the intergroup empathy gap be mitigated with strong emotion signals (i.e., tears) or specific social intentions such as the motivation to cooperate? We explored these research questions in two experiments using real-life groups that are socially important to the participants. For this, we recruited German versus Dutch supporters (Study 1) and Arsenal versus Tottenham Hotspur supporters (Study 2), thus using groups that are benign, yet extremely relevant because of the fierce rivalry between the football clubs and their fans. In both studies, participants saw facial expressions of samerace individuals presented as ingroup and outgroup members. Study 1 examined participants' facial reactions to expressions of happiness and sadness and their ability to label these expressions. Study 2 focused on participants' perceptions of genuineness of ingroup versus outgroup expressions of happiness, anger, sadness, and fear.

Findings of both studies reveal intergroup biases in emotion communication, as people react to outgroup facial expressions and evaluate them differently than facial expressions of ingroup members. In Study 1, expressions displayed by outgroup members were mimicked on average to a lower extent, potentially reflecting less pleasurable real-world interactions (Hess \& Fischer, 2013; Mauersberger \& Hess, 2019). Consistent with existing studies (Bourgeois \& Hess, 2008), participants imitated happiness displayed by the outgroup. However, expressions of sadness were not mimicked, in fact, there was some indication that these expressions elicited amusement instead. Such contrary expressions have been found in response to out-group expressions (Weyers et al., 2006). Notably, tears did not serve to increase mimicry of outgroup expressions.

In Study 2, participants evaluated ingroup expressions of happiness and fear as more genuine than the same outgroup expressions, corroborating previous findings documenting increased trust for the ingroup 
(Brewer, 1999; Dovidio et al., 2008). Both happiness (Knutson, 1996) and fear (Schachter, 1959) are affiliative expressions. Assuming that people prefer to affiliate with ingroup members, they can be expected to be more open to affiliative signals from the ingroup. Furthermore, higher trust in fear expressions of the ingroup could be related to their importance as threat signals facilitating observational learning (Keltner \& Kring, 1998; Klinnert et al., 1983; Mineka et al., 1984). Interestingly, in Study 2, sadness was perceived as more genuine in outgroup faces, suggesting that signs of weakness might be more appropriate for fans of rival football teams. This is consistent with the findings of Study 1, where participants showed reduced mimicry of intense sadness expressions displayed by ingroup members. The lower genuineness ratings of fellow Arsenal supporters' sad expressions could therefore be interpreted as a "rejection" of sadness, because this emotion is closely associated with powerlessness and help-seeking (Eisenberg et al., 1989; Keltner \& Kring, 1998; Scarantino, 2019). In both studies supporters of a given team seemed less inclined to accept that their fellow fans would show such weakness, which in turn might indicate that they are considered more suitable for supporters of the opposing team. Interestingly, sad expressions displayed by ingroup members tended to be mimicked more when they were not accompanied by tears. High-intensity tearful sad expressions seemed to elicit smiling, especially when displayed by outgroup members.

In sum, outgroup expressions seem to be mimicked to a lesser extent and judged differently than ingroup ones. Can these biases be reduced with empathyboosting manipulations such as adding tears to facial expressions or increasing participants' motivation to cooperate with the outgroup? Study 1 examined participants' reactions to, and judgments of happy and sad expressions presented with and without tears. Tears are a strong and honest emotion signal eliciting empathy and support (Hendriks \& Vingerhoets, 2006; Hendriks et al., 2008). Thus, facial expressions accompanied by tears have the potential to bypass intergroup divisions and elicit affiliative reactions and the corresponding facial mimicry (Hess \& Fischer, 2013). The findings of Study 1, however, suggest that this is not the case. Tears seemed to have a positive effect for low-intensity sadness expressions displayed by ingroup members, but sad facial expressions displayed by outgroup members and accompanied by tears seemed to elicit participants' amusement rather than empathy. This result is consistent with previous research showing the existence of 'counter-mimicry', i.e. facial expressions contrary to those shown by a disliked interaction partner (Lanzetta \& Englis, 1989; Weyers et al., 2009). As such, highlighting outgroup distress may not be an efficient way of reducing intergroup biases in emotion communication, and instead may even lead to amusement or bullying in sports-related settings involving men. This is interesting as people often claim that they would be more willing to help someone who cries (Hendriks et al., 2008). Yet, findings of Study 1 suggest that such verbal claims may not be reflected in automatic behaviors such as facial mimicry. It should be noted that, in the same study, ratings of emotion were not significantly affected by group membership. Thus, participants did not have trouble understanding the emotions of outgroup members; rather they did not react to them with empathy and facial mimicry.

Findings of Study 2 are more encouraging, when it comes to reducing intergroup bias. Here, group differences in authenticity judgments disappeared when participants had been primed with cooperation goals. This finding is in line with classic notions that positive and constructive interactions should bridge prejudice (Allport, 1954) and with other research showing that motivational factors impact emotion decoding accuracy as well as empathic reactions (Hess et al., 2016; Thibault et al., 2006). Changing participants' mindset by activating cooperation goals was sufficient to erase intergroup biases in ratings of expression genuineness.

To conclude, our studies suggest that both group membership and cooperative motives can shape how facial expressions are mimicked and interpreted. They also indicate the possibility of reducing intergroup biases in emotion communication. Besides exploring automatic facial mimicry and recognition accuracy of ingroup versus outgroup facial expressions, future research could explore how cooperative motives affect facial expressions judgements by exploring their influence on other constructs associated with intergroup bias. Such constructs could include group identification (Levine et al., 2005); feelings of similarity (Dovidio et al., 2008), empathy (Kuchenbrandt et al., 2013), and shared fate (Hornstein, 1976). One strength of the present studies is the use of meaningful 
social groups, i.e. supporters of German and Dutch football and Arsenal FC and Tottenham Hotspur. However, it is important to highlight that because of this focus on football fans, our studies examine reactions to and perceptions of facial expressions in only one setting. Future studies should explore the generalizability of the present results to other social situations and groups, including less competitive settings. For example, expressions of sadness could be more appropriate, and thus mimicked to a greater extent among social workers or clinical psychologists compared to football fans. It is also important to note that the present research involved male participants reacting to and evaluating men's faces. Given the well-documented gender differences in facial expressivity and social norms about facial expressions (e.g., Fischer \& LaFrance, 2014), it is possible that different effects would be observed for mixed or female samples. It is therefore important for future studies to examine intergroup empathy gap in more inclusive samples. Another limitation of the present research is the focus on two complementary yet distinct aspects of intergroup empathy: facial mimicry and judgments of genuineness. Although existing research suggests that mimicry may inform judgments of genuineness (Maringer et al., 2011; Rychlowska et al., 2014), the extent to which the magnitude of mimicry guides such judgments is yet to be understood (Hess \& Fischer, 2013). The same applies to the complex relationship between facial mimicry and empathy (Drimalla et al., 2019; Holland et al., 2020). Nonetheless, investigating how the presence of tears and perceptions of appropriateness of facial expressions affect facial mimicry of ingroup and outgroup faces (van der Schalk et al., 2011b) offers a promising avenue for future research, especially given recent results demonstrating strong top-down influences on facial mimicry (Kastendieck et al., 2020). Finally, given the promising findings of Study 2, it is important to test whether these effects were due to priming or to informing participants about a collaborative task with an outgroup member. Given that people tend to mimic likeable others to a greater extent (e.g., Likowski et al., 2008; McIntosh, 2006), it is also possible that introducing cooperative goals in Study 2 increased participants' facial mimicry, which should be measured in future research. Such future studies should also include measures of participants' motivation to understand ingroup and outgroup facial expressions (Murata et al., 2016).
The present research examined facial mimicry and ratings of genuineness of facial expressions displayed by fellow fans of the same versus the opposing football club. Group categorization effects occurred for emotion expressions displayed by same-race individuals, above and beyond any cultural differences in facial expressions-but were significantly reduced after inducing cooperation goals. The findings of the two studies reveal that facial mimicry as well as perceptions of genuineness of emotion expressions, used by observers as cues for trustworthiness and cooperation (e.g., Krumhuber et al., 2007), vary as a function of contextual factors and likely depend on relevant social motives. Human observers are therefore not simple emotion readout machines; their reactions to facial expressions depend on the situation and on observers' relations with the group whose member shows the expression.

Funding Open Access funding enabled and organized by Projekt DEAL.

\section{Declarations}

Conflict of interest None of the authors has a conflict of interest.

Open Access This article is licensed under a Creative Commons Attribution 4.0 International License, which permits use, sharing, adaptation, distribution and reproduction in any medium or format, as long as you give appropriate credit to the original author(s) and the source, provide a link to the Creative Commons licence, and indicate if changes were made. The images or other third party material in this article are included in the article's Creative Commons licence, unless indicated otherwise in a credit line to the material. If material is not included in the article's Creative Commons licence and your intended use is not permitted by statutory regulation or exceeds the permitted use, you will need to obtain permission directly from the copyright holder. To view a copy of this licence, visit http://creativecommons.org/licenses/by/4.0/.

\section{References}

Allport, G. W. (1954). The nature of prejudice. Perseus Books. Balliet, D., Wu, J., \& De Dreu, C. K. (2014). Ingroup favoritism in cooperation: A meta-analysis. Psychological Bulletin, 140(6), 1556.

Beaupré, M. G., \& Hess, U. (2005). Cross-cultural emotion recognition among Canadian ethnic groups. Journal of Cross-Cultural Psychology, 36, 355-370.

Bettencourt, B. A., Brewer, M. B., Croak, M. R., \& Miller, N. (1992). Cooperation and the reduction of intergroup bias: 
The role of reward structure and social orientation. Journal of Experimental Social Psychology, 28(4), 301-319.

Bijlstra, G., Holland, R. W., Dotsch, R., Hugenberg, K., \& Wigboldus, D. H. J. (2014). Stereotype associations and emotion recognition. Personality and Social Psychology Bulletin, 40(5), 567-577. https://doi.org/10.1177/ 0146167213520458

Bourgeois, P., \& Hess, U. (2008). The impact of social context on mimicry. Biological Psychology, 77, 343-352.

Brewer, M. B. (1999). The psychology of prejudice: Ingroup love and outgroup hate? Journal of Social Issues, 55(3), 429-444.

Costin, F. (1969). The scrambled sentence test: A group measure of hostility. Educational and Psychological Measurement, 29(2), 461-468.

Dimberg, U., Thunberg, M., \& Grunedal, S. (2002). Facial reactions to emotional stimuli: Automatically controlled emotional responses. Cognition and Emotion, 16, 449-472. https://doi.org/10.1080/02699930143000356

Dovidio, J., Penner, L., Albrecht, T., Norton, W., Gaertner, S., \& Shelton, J. (2008). Disparities and distrust: The implications of psychological processes for understanding racial disparities in health and health care. Social Science \& Medicine, 67(3), 478-486. https://doi.org/10.1016/j. socscimed.2008.03.019.

Drimalla, H., Landwehr, N., Hess, U., \& Dziobek, I. (2019). From face to face: the contribution of facial mimicry to cognitive and emotional empathy. Cognition and Emotion

Eisenberg, N., Fabes, R., Miller, P., Fultz, J., Shell, R., Mathy, R., \& Reno, R. (1989). Relation of sympathy and personal distress to prosocial behavior: A multimethod study. Journal Of Personality And Social Psychology, 57(1), 55-66. https://doi.org/10.1037/0022-3514.57.1.55

Elfenbein, H. A., \& Ambady, N. (2002). On the universality and cultural specificity of emotion recognition: A meta-analysis. Psychological Bulletin, 128, 203-235. https://doi.org/ 10.1037/0033-2909.128.2.203

Elfenbein, H. A., Beaupré, M. G., Levesque, M., \& Hess, U. (2007). Toward a dialect theory: Cultural differences in the expression and recognition of posed facial expressions. Emotion, 7, 131-146. https://doi.org/10.1037/1528-3542. 7.1 .131

Faul, F., Erdfelder, E., Buchner, A., \& Lang, A. (2009). Statistical power analyses using $\mathrm{G}^{*}$ Power 3.1: Testsfor correlation and regression analyses. Behavior Research Methods, 41(4), 1149-1160. https://doi.org/10.3758/brm. 41.4.1149.

Fischer, A., \& Hess, U. (2017). Mimicking emotions. Current Opinion in Psychology, 17, 151-155.

Fischer, A., \& LaFrance, M. (2014). What drives the smile and the tear: Why women are more emotionally expressive than men. Emotion Review, 7(1), 22-29. https://doi.org/10. 1177/1754073914544406

Fischer, A., \& Manstead, A. S. R. (2008). The social function of emotions. In M. Lewis, J. Haviland-Jones, \& L. F. Barrett (Eds.), Handbook of emotions (Vol. 3, pp. 456-468). Guilford Press.

Fischer, A., Pauw, L. S., \& Manstead, A. S. R. (2019). Emotion Recognition as a Social Act: The role of the expresserobserver relationship in recognizing emotions. The social nature of emotion expression (pp. 7-24). Springer.
Fitzsimons, G. M., \& Shah, J. Y. (2008). How goal instrumentality shapes relationship evaluations. Journal of Personality and Social Psychology, 95(2), 319.

Hendriks, M. C. P., Croon, M. A., \& Vingerhoets, A. J. J. M. (2008). Social reactions to adult crying: The help-soliciting function of tears. The Journal of Social Psychology, 148(1), 22-42. https://doi.org/10.3200/SOCP.148.1.22-42

Hendriks, M. C. P., \& Vingerhoets, A. J. J. M. (2006). Social messages of crying faces: Their influence on anticipated person perception, emotions and behavioural responses. Cognition \& Emotion, 20, 878-886.

Hess, U. (2021). Who to whom and why: The social nature of emotional mimicry. Psychophysiology, 58(1), e13675. https://doi.org/10.1111/psyp.13675

Hess, U., Arslan, R., Mauersberger, H., Blaison, C., Dufner, M., Denissen, J. J. A., \& Ziegler, M. (2017). Reliability of surface facial electromyography. Psychophysiology, 54, 12-23. https://doi.org/10.1111/psyp. 12676

Hess, U., Blaison, C., \& Dandeneau, S. (2017). The impact of rewards on empathic accuracy and emotional mimicry. Motivation and Emotion, 41(1), 107-112. https://doi.org/ 10.1007/s11031-016-9590-6

Hess, U., David, S., \& Hareli, S. (2016). Emotional restraint is good for men only: The influence of emotional retraint on the perception of competence. Emotion, 16, 208-213.

Hess, U., \& Fischer, A. (2013). Emotional mimicry as social regulation. Personality and Social Psychology Review, 17, 142-157. https://doi.org/10.1177/1088868312472607

Hess, U., \& Fischer, A. (2014). Emotional mimicry: Why and when we mimic emotions. Social and Personality Psychology Compass, 8, 45-57. https://doi.org/10.1111/spc3. 12083

Hess, U., \& Fischer, A. (2017). The role of emotional mimicry in intergroup relations. In H. Giles \& J. Harwood (Eds.), Oxford encyclopedia of intergroup communication. Oxford University Press.

Hess, U., \& Hareli, S. (2019). The emotion-based inferences in context (EBIC) model. The social nature of emotion expression (pp. 1-5). Springer.

Holland, A., O'Connell, G., \& Dziobek, I. (2020). Facial mimicry, empathy, and emotion recognition: A metaanalysis of correlations. Cognition and Emotion, 35(1), 150-168. https://doi.org/10.1080/02699931.2020. 1815655

Hornstein, H. A. (1976). Cruelty and kindness: A new look at aggression and altruism. Englewood Cliffs, NJ: PrenticeHall.

Hugenberg, K., \& Bodenhausen, G. V. (2003). Facing prejudice: Implicit prejudice and the perception of facial threat. Psychological Science, 14, 640-643. https://doi.org/10. 1046/j.0956-7976.2003.psci_1478.x

Kastendieck, T., Mauersberger, H., Blaison, C., Ghalib, J., \& Hess, U. (2020). Laughing at funerals and frowning at weddings: Top-down influences of context-driven social judgments on emotional mimicry. Acta Psychologica, 212, 103195.

Keltner, D., \& Kring, A. M. (1998). Emotion, social function, and psychopathology. Review of General Psychology, 2(3), 320-342.

Kirouac, G., \& Hess, U. (1999). Group membership and the decoding of nonverbal behavior. In P. Philippot, R. 
Feldman, \& E. Coats (Eds.), The social context of nonverbal behavior (pp. 182-210). Cambridge University Press.

Klinnert, M. D., Campos, J. J., Sorce, J. F., Emde, R. N., \& Svejda, M. (1983). Emotions as behavior regulators: Social referencing in infancy. In R. Plutchik \& H. Kellerman (Eds.), Emotion: Theory, research and experience (Vol. 2, pp. 57-86). Academic Press.

Knutson, B. (1996). Facial expressions of emotion influence interpersonal trait inferences. Journal of Nonverbal Behavior, 20, 165-182. https://doi.org/10.1007/ BF02281954

Krumhuber, E., Manstead, A., Cosker, D., Marshall, D., Rosin, P., \& Kappas, A. (2007). Facial dynamics as indicators of trustworthiness and cooperative behavior. Emotion, 7, 730-735.

Kuchenbrandt, D., Eyssel, F., \& Seidel, S. K. (2013). Cooperation makes it happen: Imagined intergroup cooperation enhances the positive effects of imagined contact. Group Processes \& Intergroup Relations, 16(5), 635-647.

Langner, O., Dotsch, R., Bijlstra, G., Wigboldus, D., Hawk, S., \& van Knippenberg, A. (2010). Presentation and validation of the Radboud Faces Database. Cognition \& Emotion, 24(8), 02699930903485076

Lanzetta, J. T., \& Englis, B. G. (1989). Expectations of cooperation and competition and their effects on observers' vicarious emotional responses. Journal of Personality and Social Psychology, 56, 543-554. https://doi.org/10.1037/ 0022-3514.56.4.543

Levine, M., Prosser, A., Evans, D., \& Reicher, S. (2005). Identity and emergency intervention: How social group membership and inclusiveness of group boundaries shape helping behavior. Personality and Social Psychology Bulletin, 31(4), 443-453. https://doi.org/10.1177/ 0146167204271651

Likowski, K. U., Mühlberger, A., Seibt, B., Pauli, P., \& Weyers, P. (2008). Modulation of facial mimicry by attitudes. Journal of Experimental Social Psychology, 44, 1065-1072.

Lundqvist, D., Flykt, A., \& Öhman, A. (1998). The Karolinska directed emotional faces (KDEF). CD ROM from Department of Clinical Neuroscience, Psychology section, Karolinska Institutet.

MacArthur, H. J., \& Shields, S. A. (2015). There's no crying in baseball, or is there? Male athletes, tears, and masculinity in North America. Emotion Review, 7(1), 39-46.

Maringer, M., Krumhuber, E. G., Fischer, A. H., \& Niedenthal, P. M. (2011). Beyond smile dynamics: Mimicry and beliefs in judgments of smiles. Emotion, 11(1), 181-187. https:// doi.org/10.1037/a0022596

Mauersberger, H., \& Hess, U. (2019). When smiling back helps and scowling back hurts: individual differences in emotional mimicry are associated with self-reported interaction quality during conflict interactions. Motivation and Emotion, 43(3), 471-482. https://doi.org/10.1007/s11031-0189743-x

McIntosh, D. N. (2006). Spontaneous facial mimicry, liking and emotional contagion. Polish Psychological Bulletin, 37(1), $31-42$.
Mineka, S., Davidson, M., Cook, M., \& Keir, R. (1984). Observational conditioning of snake fear in rhesus monkeys. Journal of Abnormal Psychology, 93(4), 355-372. https://doi.org/10.1037/0021-843x.93.4.355

Murata, A., Saito, H., Schug, J., Ogawa, K., \& Kameda, T. (2016). Spontaneous facial mimicry is enhanced by the goal of inferring emotional states: Evidence for moderation of "automatic" mimicry by higher cognitive processes. PLOS ONE, 11(4), https://doi.org/10.1371/journal.pone. 0153128 .

Niedenthal, P. M., \& Brauer, M. (2012). Social Functionality of Human Emotion. Annual Review of Psychology, 63(1), 259-285. https://doi.org/10.1146/annurev.psych.121208. 131605

Rodin, M. J. (1987). Who is memorable to whom: A study of cognitive disregard. Social Cognition, 5, 144-165.

Rychlowska, M., Korb, S., Brauer, M., Droit-Volet, S., Augustinova, M., Zinner, L., \& Niedenthal, P. (2014). Pacifiers disrupt adults' responses to infants' emotions. Basic and Applied Social Psychology, 36(4), 299-308. https://doi.org/10.1080/01973533.2014.915217

Sacco, D. F., \& Hugenberg, K. (2012). Cooperative and competitive motives enhance perceptual sensitivity to angry and happy facial expressions. Motivation and Emotion, 36(3), 382-395.

Scarantino, A. (2019). Affective pragmatics extended: From natural to overt expressions of emotions. The social nature of emotion expression (pp. 49-81). Springer.

Schachter, S. (1959). The psychology of affiliation: Experimental studies of the sources of gregariousness. Stanford University Press.

Schubert, T., \& Otten, S. (2002). Overlap of Self, Ingroup, and Outgroup: Pictorial Measures of Self-Categorization. Self and Identity, 1(4), 353-376. https://doi.org/10.1080/ 152988602760328012

Tajfel, H., \& Turner, J. C. (1979). An integrative theory of intergroup conflict. In W. G. Austin \& S. Worchel (Eds.), The social psychology of intergroup relations (pp. 33-48). Brooks/Cole.

Thibault, P., Bourgeois, P., \& Hess, U. (2006). The effect of group-identification on emotion recognition: The case of cats and basketball players. Journal of Experimental Social Psychology, 42, 676-683.

van der Schalk, J., Hawk, S. T., Fischer, A. H., \& Doosje, B. J. (2011a). Moving faces, looking places: Validation of the Amsterdam Dynamic Facial Expression Set (ADFES). Emotion, 11(4), 907.

van der Schalk, J., Fischer, A., Doosje, B. J., Wigboldus, D., Hawk, S., Rotteveel, M., \& Hess, U. (2011b). Convergent and divergent responses to emotional displays of ingroup and outgroup. Emotion, 11(2), 286-298. https://doi.org/10. 1037/a0022582

Warner, L. A., \& Shields, S. A. (2007). The perception of crying in women and men: Angry tears, sad tears, and the "right way" to cry. In U. Hess \& P. Philippot (Eds.), Group dynamics and emotional expression (pp. 92-117). Cambridge University Press.

Watson, R. E., Pritzker, L., \& Madison, P. (1955). Hostility in neurotics and normals. The Journal of Abnormal and Social Psychology, 50(1), 36. 
Weyers, P., Mühlberger, A., Hefele, C., \& Pauli, P. (2006). Electromyographic responses to static and dynamic avatar emotional facial expressions. Psychophysiology, 43, 450-453. https://doi.org/10.1111/j.1469-8986.2006. 00451.x

Weyers, P., Mühlberger, A., Kund, A., Hess, U., \& Pauli, P. (2009). Modulation of facial reactions to avatar emotional faces by nonconscious competition priming. Psychophysiology, 46, 328-335.
Young, S. G., \& Hugenberg, K. (2010). Mere social categorization modulates identification of facial expressions of emotion. Journal of Personality and Social Psychology, 99, 964-977. https://doi.org/10.1037/a0020400

Publisher's Note Springer Nature remains neutral with regard to jurisdictional claims in published maps and institutional affiliations. 